OPEN ACCESS

International Journal of

Environmental Research and

Public Health

ISSN 1660-4601

www.mdpi.com/journal/ijerph

Article

\title{
Odor and VOC Emissions from Pan Frying of Mackerel at Three Stages: Raw, Well-Done, and Charred
}

\author{
Jeong-Hyeon Ahn, Jan E. Szulejko *, Ki-Hyun Kim, Yong-Hyun Kim and Bo-Won Kim \\ Department of Civil and Environmental Engineering, Hanyang University, Seoul 133-791, Korea; \\ E-Mails: qq112311@naver.com (J.-H.A.); kkim61@hanyang.ac.kr (K.-H.K.); \\ inocent01@nate.com (Y.-H.K.); samsuet@nate.com (B.-W.K.) \\ * Author to whom correspondence should be addressed; E-Mail: shuleiko@hanyang.ac.kr; \\ Tel.: +82-2-2220-2326; Fax: +82-2-2220-1945.
}

External Editor: Paul B. Tchounwou

Received: 8 August 2014; in revised form: 4 November 2014 / Accepted: 6 November 2014 / Published: 14 November 2014

\begin{abstract}
Many classes of odorants and volatile organic compounds that are deleterious to our wellbeing can be emitted from diverse cooking activities. Once emitted, they can persist in our living space for varying durations. In this study, various volatile organic compounds released prior to and during the pan frying of fish (mackerel) were analyzed at three different cooking stages (stage $1=$ raw (R), stage $2=$ well-done (W), and stage 3 = overcooked/charred (O)). Generally, most volatile organic compounds recorded their highest concentration levels at stage $3(\mathrm{O})$, e.g., 465 (trimethylamine) and $106 \mathrm{ppb}$ (acetic acid). In contrast, at stage $2(\mathrm{~W})$, the lowest volatile organic compounds emissions were observed. The overall results of this study confirm that trimethylamine is identified as the strongest odorous compound, especially prior to cooking (stage $1(\mathrm{R})$ ) and during overcooking leading to charring (stage $3(\mathrm{O})$ ). As there is a paucity of research effort to measure odor intensities from pan frying of mackerel, this study will provide valuable information regarding the management of indoor air quality.
\end{abstract}

Keywords: mackerel; odorant; volatile organic compounds (VOC); sorbent tube; GC-MS 


\section{Abbreviations}

ACA

ADL

B

BA

BTA

$\mathrm{BuAc}$

CLASS

$\mathrm{CN}$

$\mathrm{CT}$

FSC

FSV

GC

HPA

HVAC

HXA

IA

IAQ

IBA

IVA

MDL

MEK

MIBK

MS

PA

PEA

PM

PPA

ppb

QA

QC

RF

RGC

$\mathrm{RH}$

RSE

$\mathrm{S}$

SBS

ST

$\mathrm{T}$

TD

TMA

TVOC

VA

VLA

VOC

WS

$\mathrm{X}$ acetic acid

activities of daily living

benzene

butyraldehyde

$n$-butyric acid

butyl acetate

compounds lacking authentic standards or surrogates

carbon number

cold trap

fixed standard concentration

fixed standard volume

gas chromatography

heptanoic acid

heating, ventilating, and air conditioning

hexanoic acid

$i$-valeraldehyde

indoor air quality

$i$-butyric acid; $i$-BuAl; $i$-butyl alcohol

$i$-valeric acid

method detection limits

methyl ethyl ketone

methyl $i$-butyl ketone

mass spectrometry

propionaldehyde

polyester aluminum

particulate matter

propionic acid

parts per billion

quality assurance

quality control

response factor

reagent grade chemical

relative humidity

relative standard error

styrene

sick building syndrome

sorbent tube

toluene

thermal desorption

trimethylamine

total VOC emissions

valeraldehyde

$n$-valeric acid

volatile organic compound

working standard

xylene 


\section{Introduction}

In recent years, most people spend an increasing amount of time indoors or in enclosed spaces, to an extent of $>90 \%$ per day at home, work, or in vehicles (5.5\%) [1]. With the increasing time spent indoors, there have been growing concerns about indoor air quality (IAQ). Numerous volatile organic compounds (VOCs) with various functional groups and odor strengths have been identified in indoor environments. Many countries worldwide have passed and enacted various IAQ regulatory laws on permissible VOC concentrations and/or requirements for the improved ventilation. The sources of odorant emissions in an enclosed space are very diverse to include cooking, garbage, smoking, toilet odor, interior materials, outgassing from furniture and construction materials, biogenic, etc. [2-5]. Cooking and food storage can release many odorous compounds such as sulfurous, nitrogeneous, volatile fatty acid, aldehyde, hydrocarbon, and alcohol compounds [6]. Chronic exposure to indoor air pollutants can induce various symptoms such as headache, fatigue, dermatitis, etc. These presenting symptoms have been commonly used to diagnose Sick Building Syndrome (SBS) which stimulated considerable public interest about the air quality of indoor environments [7].

It is reported that many compounds emitted during cooking in a house or enclosed space (especially with poor ventilation) can impact human health in various ways [8]. The options to maintain a pleasant IAQ include: masking with air deodorants, natural ventilation, or HVAC (heating, ventilating, and air conditioning) systems, their effectiveness or efficiencies are often not satisfactory [9]. Among the pollutants released during cooking, aldehydes are some of the most potent eye and skin irritants. Especially during food preparation, the level and type of VOCs emissions are strongly affected by a combination of variables such as: food ingredients, cooking oil, heating fuels, and cooking practices being employed. Apart from strong odorants, other hazardous pollutants (like carcinogens) are also emitted at different cooking stages [10]. These compounds can significantly impact human health, e.g., skin problems, headaches, respiratory diseases, etc. In case of lung cancer in women non-smokers, a number of factors (e.g., cooking practices and frequency) are one of the main causes in addition to other well-known factors (e.g., second-hand smoke) [11].

The aims of this research were to study the speciation of VOCs (and odorants) and to measure their concentrations before and during pan-frying of mackerel over a portable butane fuelled cooker. Based on this analysis, the emission characteristics of odors and VOCs were estimated. In our activities of daily living (ADL) depending on the cooking style, cooking can be the major source of pollutant emissions hazardous to human health $[12,13]$. In the preliminary work for this study, the reproducibility of IAQ parameters was investigated intensively in a series of replicate experiments on the pan-frying of mackerel [14]. Accordingly, the total VOC emissions (TVOC) can be measured at higher confidence, as reported previously in our replicate cooking experiments $(n=11)$. To learn more about the odor impact of pan-frying mackerel, a closed room indoor pollution study was done at three cooking stages (raw, well-cooked, and charred). The results of this fish frying study can offer valuable insights into odor and VOC emissions. 


\section{Experimental Section}

For the analysis of various VOC emitted at different cooking stages, samples were collected by frying mackerel on a pan over a butane fueled portable cooker simulating home-cooking. Air samples at each cooking stage were collected and analyzed. The collected samples were analyzed by GC-MS. For quantification, liquid/gaseous phase standards were prepared containing a total of 23 target compounds. These 23 target compounds were used to make quantitative predictions for compounds lacking authentic standards or surrogates (CLASS) using the carbon number concept and method $[15,16]$.

\subsection{Preparation of Working Standards (WS)}

Information on calibration and basic QA/QC is essential to obtain reliable data in the analysis of airborne VOCs. For the quantitation of VOCs emitted from fish frying, liquid working standards were prepared containing a total of 22 VOCs, i.e., aldehydes, ketones, aromatic hydrocarbons, volatile fatty acids, and an amine (Table 1). However, in the exceptional case of TMA, gaseous standards were used.

Table 1. Basic information on target (and reference) compounds detected at three different cooking stages of fish (mackerel) samples.

\begin{tabular}{|c|c|c|c|c|c|c|}
\hline Order & Group & Compound & Short Name & MW (g/mol) & Formula & CAS Number \\
\hline \multicolumn{7}{|c|}{ A. Target Compounds } \\
\hline 1 & Aldehydes & Propionaldehyde & $\mathrm{PA}$ & 58.1 & $\mathrm{C}_{3} \mathrm{H}_{6} \mathrm{O}$ & $123-38-6$ \\
\hline 2 & & Butyraldehyde & $\mathrm{BA}$ & 72.1 & $\mathrm{C}_{4} \mathrm{H}_{8} \mathrm{O}$ & $123-72-8$ \\
\hline 3 & & Isovaleraldehyde & IA & 86.1 & $\mathrm{C}_{5} \mathrm{H}_{10} \mathrm{O}$ & $590-86-3$ \\
\hline 4 & & Valeraldehyde & VA & 86.1 & $\mathrm{C}_{5} \mathrm{H}_{10} \mathrm{O}$ & $110-62-3$ \\
\hline 5 & & Methyl ethyl ketone & MEK & 72.1 & $\mathrm{C}_{4} \mathrm{H}_{8} \mathrm{O}$ & $78-93-3$ \\
\hline 6 & Ketones & Methyl isobutyl ketone & MIBK & 100 & $\mathrm{C}_{6} \mathrm{H}_{12} \mathrm{O}$ & $108-10-1$ \\
\hline 7 & & Butyl acetate & $\mathrm{BuAc}$ & 116 & $\mathrm{C}_{6} \mathrm{H}_{12} \mathrm{O}_{2}$ & $123-86-4$ \\
\hline 8 & & Isobutyl alcohol & $i$-BuAl & 74.1 & $\mathrm{C}_{4} \mathrm{H}_{10} \mathrm{O}$ & $78-83-1$ \\
\hline 9 & Aromatic & Benzene & $\mathrm{B}$ & 78.1 & $\mathrm{C}_{6} \mathrm{H}_{6}$ & $71-43-2$ \\
\hline 10 & hydrocarbons & Toluene & $\mathrm{T}$ & 92.1 & $\mathrm{C}_{7} \mathrm{H}_{8}$ & $108-88-3$ \\
\hline 11 & & $p$-Xylene & $p$-X & 106 & $\mathrm{C}_{8} \mathrm{H}_{10}$ & $106-42-3$ \\
\hline 12 & & $m$-Xylene & $m-X$ & 106 & $\mathrm{C}_{8} \mathrm{H}_{10}$ & $108-38-3$ \\
\hline 13 & & $o$-Xylene & $o-\mathrm{X}$ & 106 & $\mathrm{C}_{8} \mathrm{H}_{10}$ & $95-47-6$ \\
\hline 14 & & Styrene & $\mathrm{S}$ & 104 & $\mathrm{C}_{8} \mathrm{H}_{8}$ & $100-42-5$ \\
\hline 15 & Volatile & Acetic acid & $\mathrm{ACA}$ & 60.1 & $\mathrm{C}_{2} \mathrm{H}_{4} \mathrm{O}_{2}$ & $64-19-7$ \\
\hline 16 & fatty acids & Propionic acid & PPA & 74.1 & $\mathrm{C}_{3} \mathrm{H}_{6} \mathrm{O}_{2}$ & 79-09-4 \\
\hline 17 & & $i$-Butyric acid & IBA & 88.1 & $\mathrm{C}_{4} \mathrm{H}_{8} \mathrm{O}_{2}$ & $79-31.2$ \\
\hline 18 & & $n$-Butyric acid & BTA & 88.1 & $\mathrm{C}_{4} \mathrm{H}_{8} \mathrm{O}_{2}$ & $107-92-6$ \\
\hline 19 & & $i$-Valeric acid & IVA & 102 & $\mathrm{C}_{5} \mathrm{H}_{10} \mathrm{O}_{2}$ & $503-74-2$ \\
\hline 20 & & $n$-Valeric acid & VLA & 102 & $\mathrm{C}_{5} \mathrm{H}_{10} \mathrm{O}_{2}$ & $109-52-4$ \\
\hline 21 & & Hexanoic acid & HXA & 116 & $\mathrm{C}_{6} \mathrm{H}_{12} \mathrm{O}_{2}$ & $142-62-1$ \\
\hline 22 & & Heptanoic acid & HPA & 130 & $\mathrm{C}_{7} \mathrm{H}_{14} \mathrm{O}_{2}$ & 111-14-8 \\
\hline 23 & Amine & Trimethylamine & TMA & 59.1 & $\mathrm{C}_{3} \mathrm{H}_{9} \mathrm{~N}$ & $75-50-3$ \\
\hline
\end{tabular}


Table 1. Cont.

\begin{tabular}{|c|c|c|c|c|c|c|}
\hline Order & Group & Compound & Short Name & MW (g/mol) & Formula & CAS Number \\
\hline \multicolumn{7}{|c|}{ B. Reference Compounds } \\
\hline 1 & Aliphatic & $n$-Decane & -- & 142 & $\mathrm{C}_{10} \mathrm{H}_{22}$ & $124-18-5$ \\
\hline 2 & Hydrocarbons & $n$-Dodecane & -- & 170 & $\mathrm{C}_{12} \mathrm{H}_{26}$ & $112-40-3$ \\
\hline 3 & Aldehydes & Crotonaldehyde & -- & 70.1 & $\mathrm{C}_{4} \mathrm{H}_{6} \mathrm{O}$ & $4170-30-3$ \\
\hline 4 & & $n$-Hexanaldehyde & -- & 100 & $\mathrm{C}_{6} \mathrm{H}_{12} \mathrm{O}$ & $66-25-1$ \\
\hline 5 & & $n$-Heptanal & -- & 114 & $\mathrm{C}_{7} \mathrm{H}_{14} \mathrm{O}$ & $111-71-7$ \\
\hline 6 & & n-Octanaldehyde & -- & 128 & $\mathrm{C}_{8} \mathrm{H}_{16} \mathrm{O}$ & $124-13-0$ \\
\hline 7 & & (E,E)-2,4-Decadienal & -- & 152 & $\mathrm{C}_{10} \mathrm{H}_{16} \mathrm{O}$ & $25152-84-5$ \\
\hline 8 & & trans-2-Decenal & -- & 154 & $\mathrm{C}_{10} \mathrm{H}_{18} \mathrm{O}$ & $3913-71-1$ \\
\hline 9 & & 2-Undecenal & -- & 168 & $\mathrm{C}_{11} \mathrm{H}_{20} \mathrm{O}$ & $2463-77-6$ \\
\hline 10 & Alcohol & 1-Pentanol & -- & 88.2 & $\mathrm{C}_{5} \mathrm{H}_{12} \mathrm{O}$ & $71-41-0$ \\
\hline 11 & Haloalkane & Chloroform & -- & 119 & $\mathrm{CHCl}_{3}$ & $67-66-3$ \\
\hline
\end{tabular}

Reagent grade chemicals (RGC) with purities $>97 \%$ were purchased (Sigma-Aldrich, St Louis, MO, USA) to prepare liquid phase standards of 22 target compounds (except trimethylamine, Rigas, Daejeon, Korea). Liquid working standards (L-WS) were made by the diluting RGCs in a stepwise manner in methanol. Concentrations of the L-WSs for a four-point calibration were in the range 4.91-49.1 ng (in case of benzene, see Table 2). The calibration of these four-point L-WS was conducted at a fixed standard volume (FSV) method [17]. In case of TMA, 1002 ppb gaseous working standard (G-WS) was prepared by mixing the primary standard (5010 ppm) with nitrogen $(99.999 \%)$. For a four-point calibration of the TMA G-WS, different volumes (24.2-242 ng of TMA) were analyzed using the fixed standard concentration (FSC) approach [17] (Table 2).

\subsection{The Collection of Odorants from Fish Frying}

This research used an unfrozen filleted mackerel (see Figure 1) that was shipped from Jeju Island, South Korea the previous day and purchased from a local market. Mackerel is in high demand in South Korea and can be easily cooked. The initial weight of the mackerel (fillet) before frying was approximately $310 \mathrm{~g}$. Experiments were started approximately $1 \mathrm{~h}$ after purchase of the mackerel fillet. Mackerel fillet was pan fried using a portable butane fuelled cooker without the addition of any cooking oil to eliminate its confounding emissions. Butane is the most commonly used fuel for portable cookers in South Korea. As an oily fish, mackerel releases its own oil during cooking.

In the preliminary study, the reproducibility of the IAQ metric was ascertained from replicate pan frying of eleven mackerel fillets in a room $\left(94.5 \mathrm{~m}^{3}\right.$ volume with dimensions $6.0 \mathrm{~m} \times 6.3 \mathrm{~m} \times 2.5 \mathrm{~m}$ (height)) [14]. However, in this study, the experiments were conducted in a smaller room $\left(42.9 \mathrm{~m}^{3}\right.$ volume with dimensions $4.4 \mathrm{~m} \times 3.9 \mathrm{~m} \times 2.5 \mathrm{~m}$ (height)). In both the present and preliminary experiments, the ventilation in room was maintained at minimal level by the HVAC system. More specifically, all windows and the door were kept closed throughout sampling except briefly soon after completion of sampling when the samples were transferred to the analytical laboratory for analysis. The room temperature was kept between 23 to $27{ }^{\circ} \mathrm{C}$ with a relative humidity (RH) of $75 \%$. 
Table 2. Preparation of standards for 23 target compounds (22 in liquid- and one (TMA) in gas-phase).

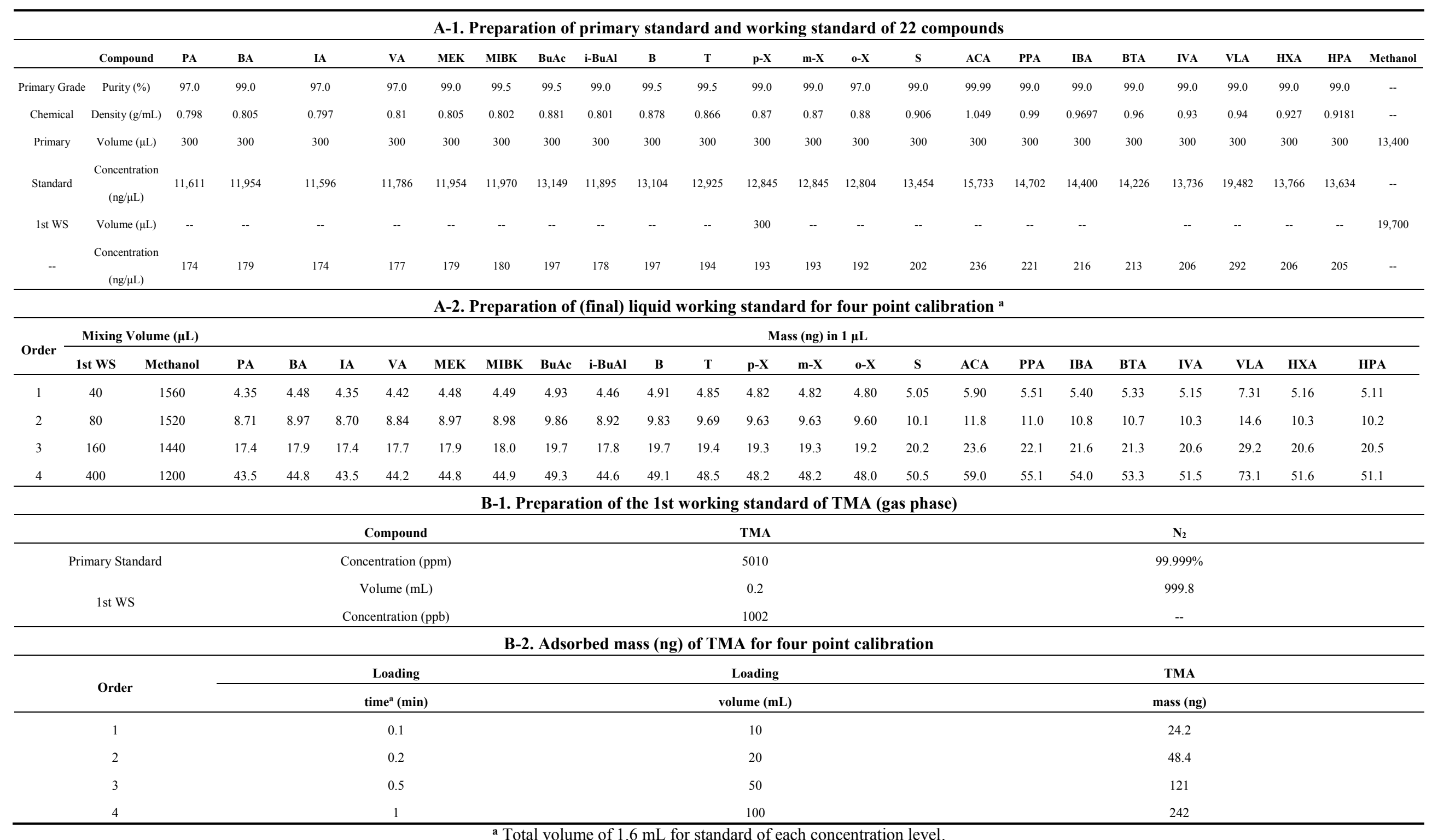


Figure 1. Basic information on mackerel frying conditions for the sample collection $(310 \mathrm{~g})$ in this study.

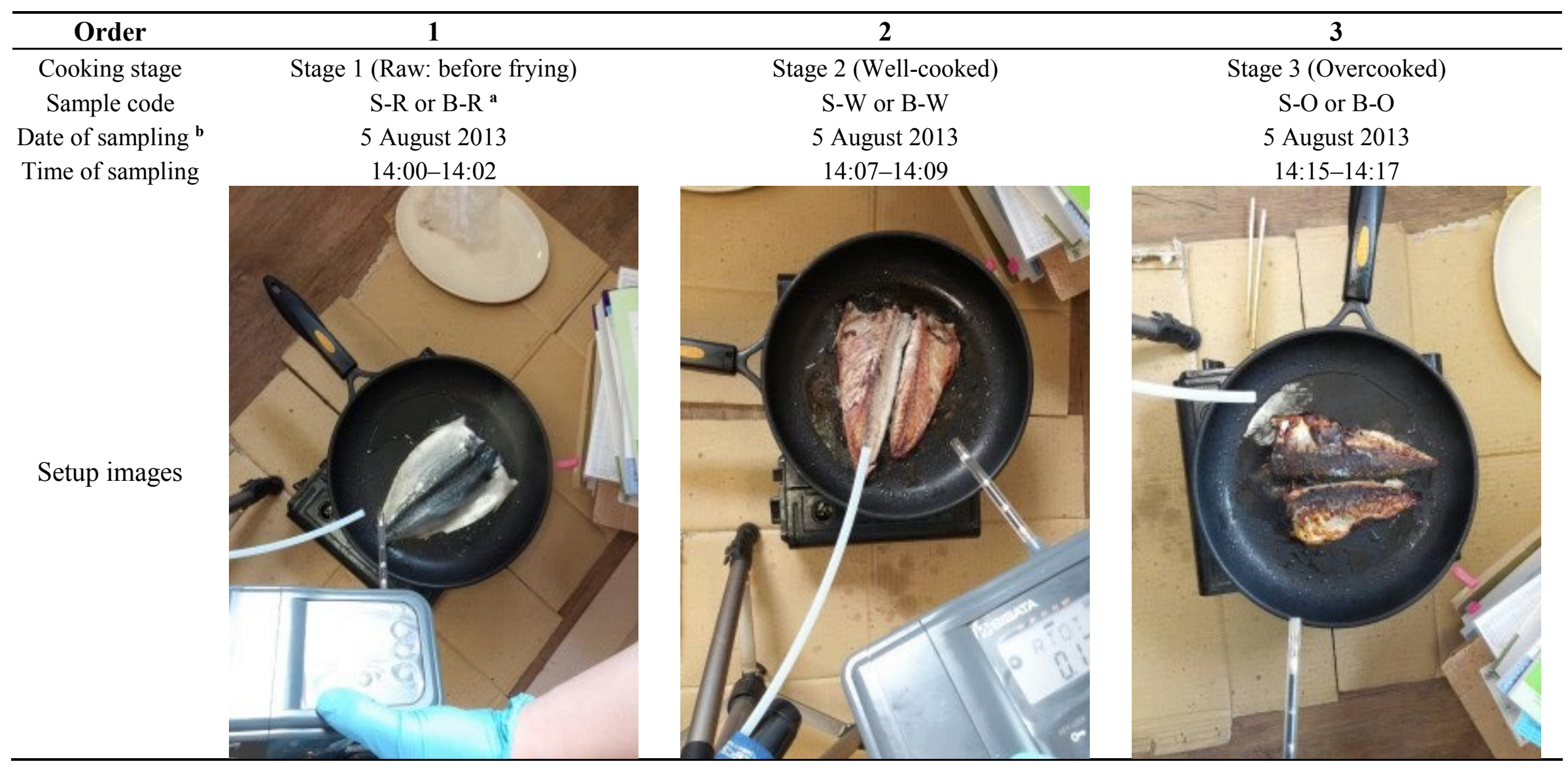

${ }^{\mathbf{a}}$ Sample code: sampling method (sorbent tube or bag) — cooking status ${ }^{\mathbf{b}}$ Mackerel was purchased at 13:00 and kept for $1 \mathrm{~h}$ at $2{ }^{\circ} \mathrm{C}$ in fridge. 
To collect VOCs released from either raw or frying mackerel, samples for VOC analysis were collected at varying frying states such as (1) stage $1=$ raw (R): started immediately once placed on the frying pan, (2) stage 2 = well-done (W): what people usually eat, and (3) stage 3 = overcooked (O): with the mackerel surface completely charred, i.e., unfit and unpleasant to eat (Figure 1). This one-time experiment was conducted to discern changes in VOCs emissions with cooking stages under the same room conditions.

Odorants released from all three different stages of fish samples were captured using both bag and sorbent tube (ST) samplers. Bag sampling was conducted with a lung sampler (ACEN Co. Ltd., Seoul, Korea) into a $10 \mathrm{~L}$ polyester aluminum (PEA) bag. Polluted air was sampled by bag sampling method $(1 \mathrm{~m}$ above the frying pan) via at Teflon (PTFE) tubing $(1 / 4 " \mathrm{OD} \times 1 / 8$ " ID $\times 1.5 \mathrm{~m})$ to simulate the approximate position of the cook's nose. Paired samples were collected simultaneously by bag and sorbent tube for comparison purposes. For analysis, the collected air samples in the PEA bag were pulled through an ST tube at a flow rate of $100 \mathrm{~mL} \cdot \mathrm{min}^{-1}$ for $2 \mathrm{~min}$. At the same sampling height, a 3-bed quartz ST packed with (1) Carbopack C (100 mg), (2) Carbopack B (70 mg), and (3) Carbopack $\times(70 \mathrm{mg})$ was also positioned for ST sampling [18]. At all three frying stage, the ST collection of airborne VOCs was made at a flow rate of $100 \mathrm{~mL} \cdot \mathrm{min}^{-1}$ for $2 \mathrm{~min}$. The recovery factor of the sampling medium does not need to be explicitly known as it is folded into the response factor as discussed in references [16] and [19]; hence, accurate VOC quantitation is assured. The reliability of this 3-bed ST setup has been validated recently by us [16].

\subsection{Instrumental Setup for Analysis}

For calibration, the L-WS was loaded into one end of ST with a microsyringe (through a temporary injection site pierced into the PTFE tube) into a constant sweeping $\mathrm{N}_{2}$ flow at $100 \mathrm{~mL} \cdot \mathrm{atm} \cdot \mathrm{min}^{-1}$ for 2 min. The ST loaded with target VOCs was analyzed by thermal desorption (TD; Markes International, Ltd, Unity, Rhondda Cynon Taff, UK) and gas chromatography-mass spectrometry (GC-MS; Shimadzu, GCMS-QP2010, Kyoto, Japan).

After an ST was loaded in the TD unit, analytes were thermally desorbed at $300{ }^{\circ} \mathrm{C}$ for 10 min to transfer analytes to the cold trap (CT) maintained at $-5{ }^{\circ} \mathrm{C}$ in the TD unit. The CT was packed with Carbopack $\mathrm{C}$ and Carbopack B in a 1:1 volume ratio. Afterwards, the analytes were desorbed off the $\mathrm{CT}$ at $320^{\circ} \mathrm{C}$ for 10 minutes and parked on CP-Wax GC column $(0.25 \mathrm{~mm} \mathrm{ID} \times 60 \mathrm{~m}, 0.25 \mu \mathrm{m}$ film thickness), The $\mathrm{GC}$ oven program was initialized at $40{ }^{\circ} \mathrm{C}$ for 10 minutes and ramped to $220{ }^{\circ} \mathrm{C}$ at $5{ }^{\circ} \mathrm{C} \cdot \mathrm{min}^{-1}$ for a total $50 \mathrm{~min}$ analytical run time (Table 3 ).

\section{Results and Discussion}

\subsection{Calibration Characteristics}

In order to quantify the VOCs released from the frying of mackerel, the basic calibration and QA experiments were conducted on 23 target VOCs by ST/TD-GC-MS. Response factors (RF) of target VOCs ranged from 7828 (propionaldehyde) to 178,910 (o-xylene). The $R^{2}$ values of calibration for all target compounds were satisfactory at $>0.99$. The results of relative standard error (RSE, \%), if used as a measure of the reproducibility of analytic technique, were $<5 \%$ (range from $0.07 \%$ ( $p$-xylene) to $4.14 \%$ 
(acetic acid)). RSE was computed by triplicate measurements on the 3rd calibration point (Table 2). Method detection limits (MDL) were determined by heptaplicate analysis of the $0.08 \mathrm{ng} \cdot \mu \mathrm{L}^{-1} \mathrm{~L}-\mathrm{WS}$. MDL ranged from $0.006 \mathrm{ng}$ (butyraldehyde) to $0.108 \mathrm{ng}$ (propionaldehyde). When applied to a $200 \mathrm{~mL}$ sample volume, the corresponding MDL in ppb was between 0.007 ( $p$-xylene) and 0.228 (propionaldehyde).

Table 3. The TD-GC-MS instrumental settings employed for the analysis of VOCs and odorants from fish cooking in this work.

\begin{tabular}{|c|c|c|c|}
\hline \multicolumn{4}{|l|}{ a. Sampling conditions } \\
\hline Sampling flow rate: & $100 \mathrm{~mL} \cdot \mathrm{min}^{-1}$ & Sorbent tube sampling temperature: & $\sim 70{ }^{\circ} \mathrm{C}$ \\
\hline Sampling volume: & $200 \mathrm{~mL}$ & Bag sampling temperature: & $25^{\circ} \mathrm{C}$ \\
\hline \multicolumn{4}{|c|}{ b. Sorbent tube desorption settings } \\
\hline Sorbent material: & \multicolumn{3}{|c|}{ Carbopack C + Carbopack B + Carbopack X (mass $=100,70,70 \mathrm{mg})$} \\
\hline Desorption flow: & \multicolumn{3}{|l|}{$50 \mathrm{~mL} \cdot \min ^{-1}$} \\
\hline Desorption time: & $10 \mathrm{~min}$ & Desorption temperature: & $300{ }^{\circ} \mathrm{C}$ \\
\hline \multicolumn{4}{|c|}{ c. Thermal desorber (Unity, Markes International, Ltd.) settings } \\
\hline Cold trap sorbent: & \multicolumn{3}{|c|}{ Carbopack C + Carbopack B (volume ratio $=1: 1)$} \\
\hline Split ratio: & $1: 5$ & Adsorption temperature: & $-5^{\circ} \mathrm{C}$ \\
\hline Split flow: & $5 \mathrm{~mL}$ & Desorption temperature: & $320^{\circ} \mathrm{C}$ \\
\hline Trap hold time: & $10 \mathrm{~min}$ & Flow path temperature: & $180^{\circ} \mathrm{C}$ \\
\hline \multicolumn{4}{|c|}{ d. GC (Shimadzu GC-2010) and Q MS (Shimadzu GCMS-QP2010) settings } \\
\hline \multicolumn{4}{|c|}{ Column: CP Wax (diameter: $0.25 \mathrm{~mm}$, length: $60 \mathrm{~m}$, and film thickness: $0.25 \mu \mathrm{m}$ ) } \\
\hline Oven settings & & MS detector settings & \\
\hline Oven temperature: & $40{ }^{\circ} \mathrm{C}(10 \mathrm{~min})$ & Ionization mode: & $\mathrm{EI}(70 \mathrm{eV})$ \\
\hline Oven ramping rate: & $5^{\circ} \mathrm{C} \cdot \min ^{-1}$ & Ion source temperature: & $230^{\circ} \mathrm{C}$ \\
\hline Max oven temperature: & $220^{\circ} \mathrm{C}(4 \mathrm{~min})$ & Interface temperature: & $230^{\circ} \mathrm{C}$ \\
\hline Total run time: & $50 \mathrm{~min}$ & TIC scan range: & $35 \sim 600 \mathrm{~m} / \mathrm{z}$ \\
\hline Carrier gas: & He $(99.999 \%)$ & Emission current: & $150 \mu \mathrm{A}$ \\
\hline Carrier Pressure: & $25.0 \mathrm{psi}$ & & \\
\hline
\end{tabular}

Out of the 23 target VOCs, only 11 VOCs were frequently detected in the fish frying air samples analyzed by GC-MS. For the non-target and reference VOCs, their RF values were estimated using predictive equations (Figure 2) based on the carbon number $(\mathrm{CN})$ concept using the RF values of a training set comprising of 23 target compounds [16]. The $R^{2}$ value of the predictive equation showed satisfactory linearity (0.9227). As a result, the RF of chloroform with the lowest carbon number $(\mathrm{CN}=1)$ was predicted to be 20,545 , whereas the RF of n-dodecane with the largest carbon number $(\mathrm{CN}=12)$ was predicted to be 246,540 . It should be noted that the RF of chloroform is probably $\sim 60,000$ which is about $1 / 3$ for that of xylene $(\sim 180,000)$ based on the work of Szulejko and Kim [20]. The predicted $R F$ values $>180,000$ are unrealistic, as those values are far above the maximum instrument intrinsic $R F$ of $\sim 180,000$ (i.e., bias due to sorbent tube breakthrough is minimal) in this experiment [19]. However, in this study, it needs reasonably good estimates for RF for both target compounds and reference compounds. Hence, the estimated RF values above 180,000 were used as is through the approximation based on the carbon number concept. The calculated MDLs of the 
non-target compounds (11 VOCs) based on predictive RF vs. CN correlation ranged from $0.026 \mathrm{ng}$ ( $n$-dodecane) to $0.318 \mathrm{ng}$ (chloroform). For a $200 \mathrm{~mL}$ sample volume, the predicted MDLs corresponded to 0.004 to $0.065 \mathrm{ppb}$, respectively (Table 4 ).

Figure 2. Predictive equation based on carbon number approach for quantification of non-target (reference) compounds.

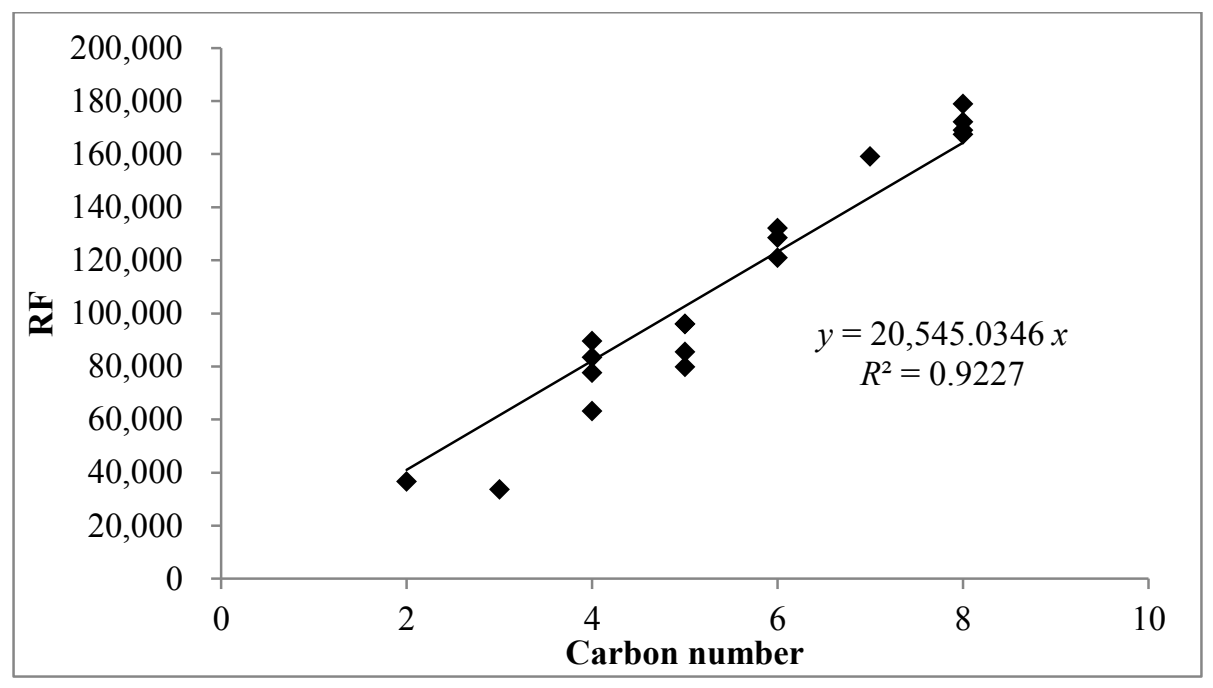

\subsection{Comparison of Concentrations between Bag Sampling and Sorbent Tube Sampling Method}

In this research, two different sampling methods (bag vs. sorbent tube sampling method) were compared. One of the sampling comparative factors to consider is the possible bias due to the high air temperature (in the vicinity of the sampling point). In case of bag sampling method, the end of sniffer line is heated by the convection plume from the BBQ. However, the bag (B) being remote from the sampling point is near room temperature $\left(25^{\circ} \mathrm{C}\right)$ and sample losses in the PTFE sniffer line is expected to be minimal [21]. In contrast, the temperature of the sorbent tube $(\mathrm{S})$ was as high as $\left(\sim 70 \pm 5^{\circ} \mathrm{C}\right)$ and variable; this may lead to sorbent bed breakthrough for the lighter VOCs (e.g., acetaldehyde and propionaldehyde (not detected)).

Inspection of the $(\mathrm{S} / \mathrm{B})$ ratios of VOCs in Table 5 showed fair to good agreement $(>0.67$ and $\leq 1)$ at stage $1(\mathrm{R})$ when the ST temperature was near room temperature and hence reduced breakthrough. Both sampling methods gave similar VOC concentration results. However, at stage 2 (W), most of the compounds (S/B) ratios were low showing negative bias except aromatic compounds (toluene, $p$-, $m$-, $o$-xylene, and styrene, i.e., not expected to exhibit breakthrough). The lowest ratio was $n$-valeric acid (0.14) in stage $2(\mathrm{~W})$ and the highest ratio was heptanoic acid (12.5) in stage $3(\mathrm{O})$. The $\mathrm{S} / \mathrm{B}$ ratio of toluene, one of the aromatic compounds (having large breakthrough volume at $70{ }^{\circ} \mathrm{C}$ ), was 0.70 (stage $1(\mathrm{R})$ ), 0.91 (stage $2(\mathrm{~W})$ ), and 1.11 (stage $3(\mathrm{O})$ ). This implies that VOC concentrations determined by the bag sampling approach were higher than sorbent tube sampling approach, although the aromatic compounds showed the least relative bias due to the minimal breakthrough. On the other hand, most of the compounds measured in stage $3(\mathrm{O})$ showed positive bias (sorbent tube vs. bag sampling) (Figure 3). Consequently, the temperature in the vicinity of the sorbent tube during frying is suspected to be the main cause of biases when sampling VOCs. Because of noticeable ST biases under 
this study conditions, the bag sampling data are discussed in greater detail than the ST data for in-depth analysis of VOCs released from fish frying at different stages unless specified otherwise.

Table 4. Results of ST-TD-GC-MS based-calibration of VOC and the basic QA parameters determined in this study: comparison of response factor $(\mathrm{RF}), R^{2}$, and relative standard error (RSE, \%) and method detection limit (MDL, ng and ppb).

\begin{tabular}{|c|c|c|c|c|c|c|c|}
\hline \multirow{2}{*}{ Order } & \multirow{2}{*}{ Group } & \multirow{2}{*}{ Compound } & \multirow{2}{*}{ RF } & \multirow{2}{*}{$R^{2}$} & \multirow{2}{*}{$\operatorname{RSE}^{a}(\%)$} & \multicolumn{2}{|c|}{ MDL } \\
\hline & & & & & & (ng) & $(p p b)^{b}$ \\
\hline \multicolumn{8}{|c|}{ A. Target compounds } \\
\hline 1 & Aldehydes & Propionaldehyde & 7828 & 0.9923 & 3.01 & 0.108 & 0.228 \\
\hline 2 & & Butyraldehyde & 63,131 & 0.9927 & 0.63 & 0.006 & 0.011 \\
\hline 3 & & Isovaleraldehyde & 95,981 & 0.9960 & 0.89 & 0.010 & 0.015 \\
\hline 4 & & Valeraldehyde & 79,889 & 0.9957 & 3.18 & 0.026 & 0.037 \\
\hline 5 & & Methyl ethyl ketone & 83,474 & 0.9938 & 0.87 & 0.037 & 0.063 \\
\hline 6 & Ketones & Methyl isobutyl ketone & 132,143 & 0.9974 & 0.91 & 0.008 & 0.010 \\
\hline 7 & & Butyl acetate & 128,506 & 0.9924 & 1.27 & 0.015 & 0.016 \\
\hline 8 & & Isobutyl alcohol & 89,544 & 0.9962 & 0.83 & 0.023 & 0.037 \\
\hline 9 & & Benzene & 120,914 & 0.9925 & 1.23 & 0.011 & 0.017 \\
\hline 10 & & Toluene & 159,105 & 0.9932 & 1.05 & 0.034 & 0.045 \\
\hline 11 & Aromatic & $p$-Xylene & 172,208 & 0.9905 & 0.07 & 0.006 & 0.007 \\
\hline 12 & hydrocarbons & $m$-Xylene & 167,521 & 0.9925 & 1.56 & 0.015 & 0.017 \\
\hline 13 & & $o$-Xylene & 178,910 & 0.9911 & 1.13 & 0.019 & 0.022 \\
\hline 14 & & Styrene & 169,088 & 0.9921 & 1.82 & 0.017 & 0.020 \\
\hline 15 & & Acetic acid & 36,696 & 0.9919 & 4.14 & 0.036 & 0.072 \\
\hline 16 & & Propionic acid & 33,591 & 0.9954 & 2.47 & 0.039 & 0.064 \\
\hline 17 & & $i$-Butyric acid & 75,064 & 0.9910 & 1.26 & 0.017 & 0.023 \\
\hline 18 & Volatile & $n$-Butyric acid & 77,611 & 0.9944 & 1.86 & 0.017 & 0.023 \\
\hline 19 & fatty acids & $i$-Valeric acid & 96,075 & 0.9958 & 0.72 & 0.014 & 0.016 \\
\hline 20 & & $n$-Valeric acid & 85,543 & 0.9952 & 0.55 & 0.015 & 0.018 \\
\hline 21 & & Hexanoic acid & 85,823 & 0.9971 & 0.13 & 0.015 & 0.016 \\
\hline 22 & & Heptanoic acid & 87,487 & 0.9968 & 1.09 & 0.015 & 0.014 \\
\hline 23 & Amine $^{c}$ & Trimethylamine & 27,952 & 0.9988 & -- & 0.047 & 0.097 \\
\hline \multicolumn{8}{|c|}{ B. Reference compounds ${ }^{c}$} \\
\hline 1 & Aliphatic & $n$-Decane & 205,450 & -- & -- & 0.032 & 0.005 \\
\hline 2 & hydrocarbons & $n$-Dodecane & 246,540 & -- & -- & 0.026 & 0.004 \\
\hline 3 & & Crotonaldehyde & 82,180 & -- & -- & 0.079 & 0.028 \\
\hline 4 & & $n$-Hexanaldehyde & 123,270 & -- & -- & 0.053 & 0.013 \\
\hline 5 & Aldehydes & $n$-Heptanal & 143,815 & -- & -- & 0.045 & 0.010 \\
\hline 6 & & n-Octanaldehyde & 164,360 & -- & -- & 0.040 & 0.008 \\
\hline 7 & & $(E, E)-2,4$-Decadienal & 205,450 & -- & -- & 0.032 & 0.005 \\
\hline 8 & & trans-2-Decenal & 205,450 & -- & -- & 0.032 & 0.005 \\
\hline 9 & & 2-Undecenal & 225,995 & -- & -- & 0.029 & 0.004 \\
\hline 10 & Alcohol & 1-Pentanol & 102,725 & -- & -- & 0.064 & 0.018 \\
\hline 11 & Haloalkane & Chloroform & 20,545 & -- & -- & 0.318 & 0.065 \\
\hline
\end{tabular}

${ }^{a}$ Triplicate analyses of the final WS (corresponding to the 3 rd calibration point); ${ }^{b}$ For the calculation of MDL (in ppb), sample volume of $200 \mathrm{~mL}$ was assumed; ${ }^{\mathrm{c}}$ Calibration was made by gaseous standard. 
Figure 3. Comparison of concentration (ppb) of all compounds between three different cooking stages.

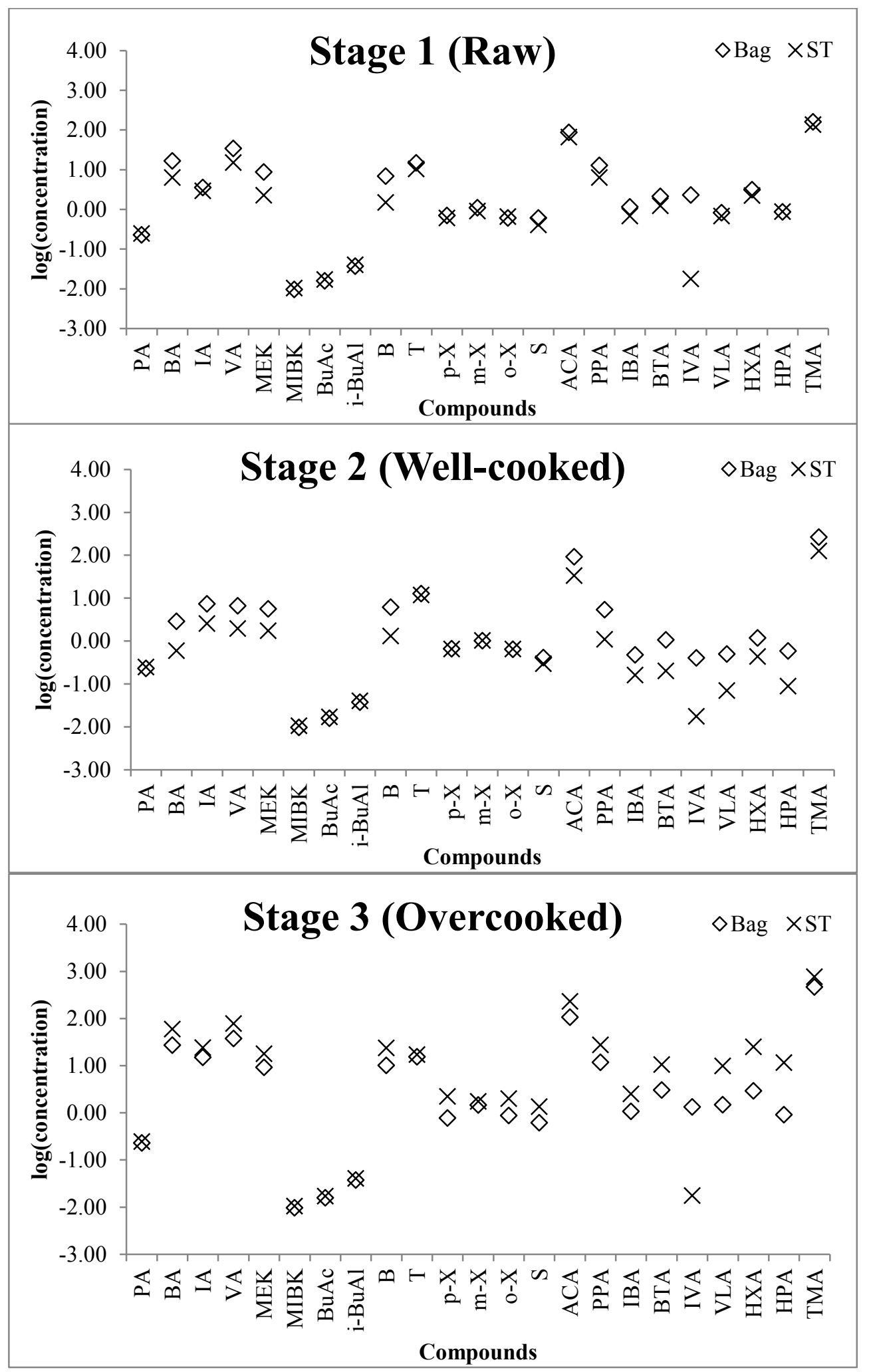

\subsection{The Evaluation of Odorants Emitted from Mackerel at Different Frying Stages}

In this research, the mackerel cooking states were classified according to the extent of frying. A total of 19 VOCs out of all 23 target VOCs (except four VOCs: PA, MIBK, BuAc, and $i$-BuAl) were 
detected in all environmental samples (Table 5A). In case of TMA, the well-known cause of fishy smell [22,23] was observed at 160 and $265 \mathrm{ppb}$ at stage $1(\mathrm{R})$ and stage $2(\mathrm{~W})$, respectively. In the present work, the highest concentration was observed at stage $3(\mathrm{O})$ at 465 ppb. ACA was 86.7, 92.5, and $106 \mathrm{ppb}$ and VA was also 34.4, 6.61, and $37.7 \mathrm{ppb}$ (bag sampling) at each stage.

By applying the RFs values estimated from the predictive equation based on carbon number [16,24], the 11 reference VOCs were quantified as explained above. The 11 reference VOCs consisted of aliphatic hydrocarbons $(n=2)$, aldehydes $(n=7)$, an alcohol $(n=1)$ and one other $(n=1)$. It is noteworthy that many of the reference compounds in the aldehyde group were detected at relatively high concentrations. In stage $1(\mathrm{R})$, crotonaldehyde and $n$-hexanaldehyde recorded approximately 51.7 and $46.3 \mathrm{ppb}$, respectively.

Inspection of the overall patterns of emitted compounds showed that their values at stage 1 (R) and 2 (W) had almost similar profiles. However, the concentrations at stage 3 (O) tended to peak sharply. Consequently, the trend of pollutant emissions was seen on the order of stage $3(\mathrm{O})>1(\mathrm{R}) \geqslant 2(\mathrm{~W})$ in that order. Additionally, in our recent study on the reproducibility of pollutants released from cooking [14], aldehydes, acetaldehyde, isovaleraldehyde, and valeraldehyde averaged 99.3, 3.96 and $12.2 \mathrm{ppb}$, respectively. Compared with this experiment, concentration especially in stage $3(\mathrm{O})$ of isovaleraldehyde and valeraldehyde concentraions were higher than previous research.

\subsection{The Evaluation of Odor Intensity at Each Frying Stage}

Of the available approaches for assessing and interpreting odor strength of VOCs and odorants, we selected the odor intensity (OI) concept. For this assessment, concentration of 16 odorants measured in this work was converted into OI based on the related formula proposed by [25] (Figure 4). The sum of odor intensity (SOI) for comprehensive comparisons (with the literature) was also calculated from OI of each compound as follows (Equation (1)):

$$
\mathrm{SOI}=\log (10 \mathrm{OI}(1)+10 \mathrm{OI}(2)+\ldots+10 \mathrm{OI}(\mathrm{n}))
$$

Using this formula, SOI values calculated at each cooking stage were 4.05, 4.12, and 4.43. In line with the general expectation, the highest SOI was observed at stage $3(\mathrm{O})$ overcooked. Inspection of the OI values for each compound showed that TMA was consistently larger at all stages 3.84 (stage 1 (R)), 4.04 (stage $2(\mathrm{~W})$ ), and 4.26 (stage $3(\mathrm{O})$ ). From this result, TMA was by far the dominant compound contributing to the SOI. On the other hand, PA and MIBK being below the MDL made no contribution to SOI (Table 6).

Prior work on TMA emissions from mackerel gave an OI value of $\sim 5.25$ [26]. The OI value of TMA in this work averaged 4.00 (stage $1(\mathrm{R})=3.84$, stage $2(\mathrm{~W})=4.04$, stage $3(\mathrm{O})=4.26$ ) and was relatively lower than previously reported. TMA is the most potent odorant of all analyzed target compounds in this work. TMA is also a significant source of malodor in both not only in fresh fish but also in overcooked fish. Analysis of various environmental samples reported in the literature revealed that there are many other compounds in food stuffs contributing to the SOI. For example, sulfur compounds $\left(\mathrm{H}_{2} \mathrm{~S}\right.$, $\mathrm{CH}_{3} \mathrm{SH}$, DMS, DMDS) are major malodorants emitted when roasting coffee $(\mathrm{SOI}=6.42)$ and from boiled egg $(\mathrm{SOI}=4.09)[27,28]$. In addition, SOI of roasting coffee beans and frying cabbage recorded 6.50 and 4.52, respectively [29]. 
Table 5. Concentration (ppb) and ratio between the two sampling methods (sorbent tube/bag (S/B)) of VOCs measured from gases samples collected at each frying stage.

\begin{tabular}{|c|c|c|c|c|c|c|c|c|c|c|c|}
\hline \multirow[t]{2}{*}{ Order } & \multirow[t]{2}{*}{ Group } & \multirow[t]{2}{*}{ Compound } & \multicolumn{3}{|c|}{$\begin{array}{c}\text { Concentration (ppb) by Bag Method } \\
\text { at Each Stage }\end{array}$} & \multicolumn{3}{|c|}{$\begin{array}{l}\text { Concentration (ppb) by Sorbent } \\
\text { Tube Method at Each Stage }\end{array}$} & \multicolumn{3}{|c|}{ Ratio (S/B) of VOCs } \\
\hline & & & B-R ${ }^{\mathbf{a}}$ & B-W & B-O & S-R & S-W & S-O & $\mathbf{R}$ & $\mathbf{W}$ & $\mathbf{O}$ \\
\hline \multicolumn{12}{|c|}{ A. Target compounds } \\
\hline 1 & Aldehydes & Propionaldehyde & 0.228 & 0.228 & 0.228 & 0.247 & 0.247 & 0.247 & -- & -- & -- \\
\hline 2 & & Butyraldehyde & 16.6 & 2.88 & 27.1 & 6.36 & 0.60 & 59.6 & 0.38 & 0.21 & 2.20 \\
\hline 3 & & Isovaleraldehyde & 3.53 & 7.34 & 15.0 & 2.92 & 2.56 & 24.1 & 0.83 & 0.35 & 1.61 \\
\hline 4 & & Valeraldehyde & 34.4 & 6.61 & 37.7 & 15.1 & 1.97 & 78.2 & 0.44 & 0.30 & 2.07 \\
\hline 5 & & Methyl ethyl ketone & 8.81 & 5.61 & 9.16 & 2.28 & 1.75 & 17.8 & 0.26 & 0.31 & 1.94 \\
\hline 6 & Ketones & Methyl isobutyl ketone & 0.010 & 0.010 & 0.010 & 0.011 & 0.011 & 0.011 & -- & -- & -- \\
\hline 7 & & Butyl acetate & 0.016 & 0.016 & 0.016 & 0.017 & 0.017 & 0.017 & -- & -- & -- \\
\hline 8 & & Isobutyl alcohol & 0.037 & 0.037 & 0.037 & 0.041 & 0.041 & 0.041 & -- & -- & -- \\
\hline 9 & & Benzene & 6.83 & 6.14 & 10.1 & 1.49 & 1.31 & 23.9 & 0.22 & 0.21 & 2.37 \\
\hline 10 & & Toluene & 14.9 & 12.8 & 15.5 & 10.5 & 11.7 & 17.2 & 0.71 & 0.92 & 1.11 \\
\hline 11 & Aromatic & $p$-Xylene & 0.71 & 0.66 & 0.78 & 0.61 & 0.65 & 2.24 & 0.86 & 0.98 & 2.89 \\
\hline 12 & hydrocarbons & $m$-Xylene & 1.10 & 1.02 & 1.47 & 0.90 & 1.04 & 1.76 & 0.82 & 1.02 & 1.20 \\
\hline 13 & & $o$-Xylene & 0.60 & 0.64 & 0.88 & 0.66 & 0.66 & 1.99 & 1.09 & 1.03 & 2.27 \\
\hline 14 & & Styrene & 0.61 & 0.41 & 0.62 & 0.41 & 0.30 & 1.36 & 0.67 & 0.72 & 2.21 \\
\hline 15 & & Acetic acid & 86.7 & 92.5 & 106 & 66.7 & 33.3 & 232 & 0.77 & 0.36 & 2.18 \\
\hline 16 & & Propionic acid & 12.8 & 5.37 & 11.7 & 6.39 & 1.10 & 27.5 & 0.50 & 0.20 & 2.34 \\
\hline 17 & & $i$-Butyric acid & 1.15 & 0.48 & 1.07 & 0.68 & 0.16 & 2.51 & 0.59 & 0.33 & 2.35 \\
\hline 18 & Volatile & $n$-Butyric acid & 2.15 & 1.06 & 3.04 & 1.24 & 0.20 & 10.5 & 0.58 & 0.19 & 3.46 \\
\hline 19 & fatty acids & $i$-Valeric acid & 2.30 & 0.40 & 1.34 & 0.018 & 0.018 & 0.018 & - & - & - \\
\hline 20 & & $n$-Valeric acid & 0.83 & 0.50 & 1.48 & 0.68 & 0.07 & 9.9 & 0.82 & 0.14 & 6.69 \\
\hline 21 & & Hexanoic acid & 3.15 & 1.18 & 2.93 & 2.22 & 0.44 & 24.9 & 0.71 & 0.37 & 8.51 \\
\hline 22 & & Heptanoic acid & 0.87 & 0.59 & 0.92 & 0.88 & 0.09 & 11.5 & 1.01 & 0.15 & 12.56 \\
\hline 23 & Amine & Trimethylamine & 160 & 265 & 465 & 137 & 126 & 772 & 0.86 & 0.47 & 1.66 \\
\hline
\end{tabular}

${ }^{a}$ Bag sampling (B), Sorbent tube sampling (S)-Stage $1=$ raw (R), 2 = well-cooked (W), 3 = overcooked (O). 
Table 5. Cont.

\begin{tabular}{|c|c|c|c|c|c|c|c|c|c|c|c|}
\hline \multirow[t]{2}{*}{ Order } & \multirow[t]{2}{*}{ Group } & \multirow[t]{2}{*}{ Compound } & \multicolumn{3}{|c|}{$\begin{array}{c}\text { Concentration (ppb) by Bag Method } \\
\text { at Each Stage }\end{array}$} & \multicolumn{3}{|c|}{$\begin{array}{c}\text { Concentration (ppb) by Sorbent } \\
\text { Tube Method at Each Stage } \\
\end{array}$} & \multicolumn{3}{|c|}{ Ratio (S/B) of VOCs } \\
\hline & & & B-R ${ }^{\mathbf{a}}$ & B-W & B-O & S-R & S-W & S-O & $\mathbf{R}$ & $\mathbf{W}$ & $\mathbf{O}$ \\
\hline \multicolumn{12}{|c|}{ B. Reference compounds } \\
\hline 1 & Aliphatic & $n$-Decane & 1.46 & 0.97 & 2.33 & 1.00 & 0.93 & 4.29 & 0.69 & 0.96 & 1.84 \\
\hline 2 & hydrocarbons & $n$-Dodecane & 0.88 & 0.42 & 1.13 & 0.19 & 0.09 & 1.94 & 0.21 & 0.20 & 1.72 \\
\hline 3 & & Crotonaldehyde & 28.0 & 4.96 & 51.7 & 12.3 & 0.90 & 111 & 0.44 & 0.18 & 2.14 \\
\hline 4 & & $n$-Hexanaldehyde & 46.3 & 10.3 & 42.7 & 21.5 & 2.95 & 90.0 & 0.46 & 0.29 & 2.11 \\
\hline 5 & Aldehydes & $n$-Heptanal & 13.4 & 2.28 & 18.3 & 6.76 & 0.79 & 45.4 & 0.50 & 0.35 & 2.48 \\
\hline 6 & & n-Octanaldehyde & 7.46 & 2.44 & 10.5 & 3.94 & 0.51 & 32.0 & 0.53 & 0.21 & 3.06 \\
\hline 7 & & $(E, E)-2,4$-Decadienal & 5.54 & 1.01 & 3.96 & 9.38 & 0.45 & 31.3 & 1.69 & 0.45 & 7.92 \\
\hline 8 & & trans-2-Decenal & 14.7 & 2.14 & 13.5 & 11.2 & 0.84 & 62.9 & 0.76 & 0.39 & 4.65 \\
\hline 9 & & 2-Undecenal & 5.85 & 1.10 & 5.07 & 9.29 & 0.56 & 50.7 & 1.59 & 0.51 & 10.00 \\
\hline 10 & Alcohol & 1-Pentanol & 24.7 & 4.50 & 19.3 & 12.8 & 1.65 & 68.0 & 0.52 & 0.37 & 3.52 \\
\hline 11 & Haloalkane & Chloroform & 8.74 & 49.9 & 55.1 & 18.0 & 63.4 & 53.2 & 2.06 & 1.27 & 0.96 \\
\hline
\end{tabular}

a Bag sampling (B), Sorbent tube sampling (S)—Stage $1=\operatorname{raw}(\mathrm{R}), 2=\operatorname{well}-\operatorname{cooked}(\mathrm{W}), 3=\operatorname{overcooked}(\mathrm{O})$. 
Figure 4. Comparison of odor intensity (OI) values of target compounds measured at different cooking stages (bag sampling).

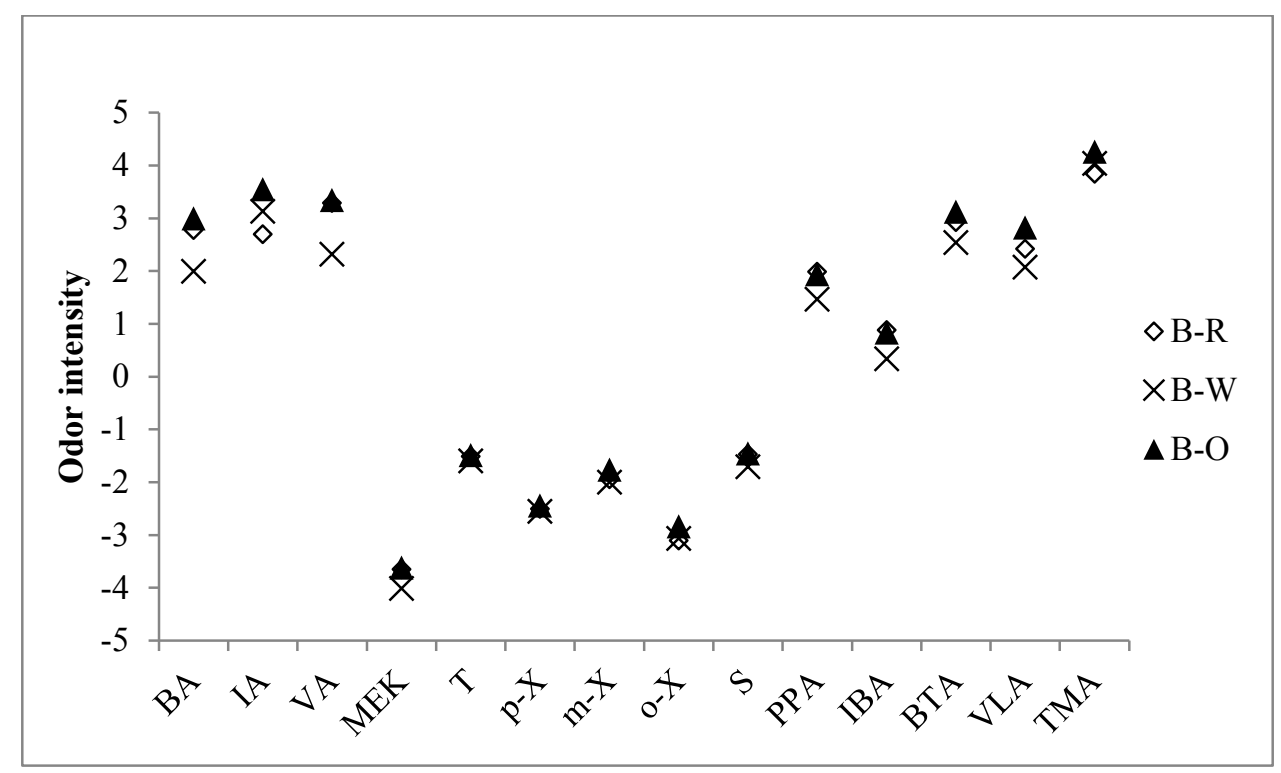

Table 6. Odor intensity (OI) formula of each compound and sum of odor intensity (SOI).

\begin{tabular}{|c|c|c|c|c|c|c|}
\hline \multirow{2}{*}{ Order } & \multirow{2}{*}{ Group } & \multirow{2}{*}{ Compound } & \multirow{2}{*}{ OI formula $a^{a}$} & \multicolumn{3}{|c|}{ OI } \\
\hline & & & & B-R & B-W & B-O \\
\hline 1 & Aldehydes & Propionaldehyde & $Y=1.010 \log X+3.86$ & ND & ND & ND \\
\hline 2 & & Butyraldehyde & $Y=1.030 \log X+4.61$ & 2.78 & 1.99 & 3.00 \\
\hline 3 & & Isovaleraldehyde & $Y=1.350 \log X+6.01$ & 2.70 & 3.13 & 3.55 \\
\hline 4 & & Valeraldehyde & $\mathrm{Y}=1.360 \log \mathrm{X}+5.28$ & 3.29 & 2.32 & 3.34 \\
\hline 5 & Ketones & Methyl ethyl ketone & $Y=1.850 \log X+0.149$ & -3.65 & -4.01 & -3.62 \\
\hline 6 & & Methyl isobutyl ketone & $Y=1.650 \log X+2.27$ & ND & ND & ND \\
\hline 7 & & Toluene & $Y=1.400 \log X+1.05$ & -1.51 & -1.60 & -1.49 \\
\hline 8 & Aromatic & $p$-Xylene & $Y=1.570 \log X+2.44$ & -2.51 & -2.56 & -2.44 \\
\hline 9 & hydrocarbons & $m$-Xylene & $Y=1.460 \log X+2.37$ & -1.95 & -2.00 & -1.77 \\
\hline 10 & & $o$-Xylene & $Y=1.660 \log X+2.24$ & -3.10 & -3.07 & -2.84 \\
\hline 11 & & Styrene & $Y=1.420 \log X+3.10$ & -1.47 & -1.71 & -1.46 \\
\hline 12 & & Propionic acid & $Y=1.380 \log X+4.60$ & 1.99 & 1.47 & 1.94 \\
\hline 13 & Volatile & $i$-Butyric acid & $Y=1.430 \log X+5.08$ & 0.88 & 0.33 & 0.83 \\
\hline 14 & fatty acids & $n$-Butyric acid & $\mathrm{Y}=1.290 \log \mathrm{X}+6.37$ & 2.93 & 2.53 & 3.12 \\
\hline 15 & & $n$-Valeric acid & $Y=1.580 \log X+7.29$ & 2.42 & 2.07 & 2.82 \\
\hline 16 & Amine & Trimethylamine & $Y=0.901 \log X+4.56$ & 3.84 & 4.04 & 4.26 \\
\hline \multicolumn{3}{|c|}{ SOI $^{\mathrm{c}}$} & -- & 4.05 & 4.12 & 4.43 \\
\hline
\end{tabular}

${ }^{\mathrm{a}}$ Refer to Nagata [25] X: concentration (ppm), and Y: odor intensity; ${ }^{\mathrm{b}}$ Not calculated; ${ }^{\mathrm{c}} \mathrm{SOI}=\log \left(10^{\wedge} \mathrm{OI}_{(1)}+\right.$ $\left.10^{\wedge} \mathrm{OI}_{(2)}+\ldots+10^{\wedge} \mathrm{OI}_{(\mathrm{n})}\right)$.

\section{Conclusions}

In this work, various VOCs released during the pan frying of fish (mackerel) were analyzed at three different levels of cooking steps. We collected environmental air samples into sorbent tube and bag samplers for VOC quantification. The samples collected by the sorbent tube method were subject to 
large bias (both positive and negative) relative to the bag samples due to the sorbent been exposed to high unregulated air temperatures. The principal odorant emissions were generally in this order: stage $3(\mathrm{O})>$ stage $1(\mathrm{R}) \geqslant$ stage $2(\mathrm{~W})$. Of the emitted VOCs from fish frying, TMA is especially a potent source of odor and recorded its highest concentration of $465 \mathrm{ppb}$ at stage $3(\mathrm{O})$. Similarly, ACA was also recorded its highest concentration (106 ppb) at stage $3(\mathrm{O})$. If the present work's OI data are compared. TMA appears to be by far the largest contributor to the SOI at all stages. Therefore, TMA is an important odorant released from both fresh and overcooked fish. The concentrations of the reference 11 VOCs along with the 23 target compounds were calculated using the carbon number concept. A number of aldehyde compounds were detected exceeded the maximum regulatory IAQ limits in these experiments. The highest VOCs concentrations were found at stage $3(\mathrm{O})$. The degree of fish frying simultaneously increased both the emission of odorants and VOCs.

The results of this study clearly suggest that various volatiles released from cooking activities should have a very major impact on human malodor perception, so adequate ventilation is an important factor for indoor air quality control when cooking inside [30]. Many types of hazardous compounds against to our wellbeing are emitted in massive quantities during cooking activities and can persist to cause the potential chronic diseases. Thus, we hope that this research outputs can contribute to a better understanding on the serious one of such issues and provide some basic tactics to control indoor air quality.

\section{Acknowledgments}

This work was supported by a research fund from Hanyang University (HY-2014-G).

\section{Author Contributions}

Jeong-Hyeon Ahn collected the samples during the fish frying experiments, analyzed the data, conducted the literature survey, and drafted the manuscript. Jan E. Szulejko (assistant principal investigator) and Ki-Hyun Kim (principal investigator) reviewed and edited the draft manuscript for scientific content. In addition, they performed the overall internal review (with assistance from all authors). Yong-Hyun Kim made the sorbent tubes and performed the GC-MS calibration experiments. Bo-Won Kim collected the samples during the fish frying experiments and analyzed the data.

\section{Conflicts of Interest}

The authors declare no conflict of interest.

\section{References}

1. Klepeis, N.E.; Nelson, W.C.; Ott, W.R.; Robinson, J.P.; Tsang, A.M.; Switzer, P.; Behar, J.V.; Hern, S.C.; Engelmann, W.H. The National Human Activity Pattern Survey (NHAPS): A resource for assessing exposure to environmental pollutants. J. Expo. Anal. Environ. Epidemiol. 2001, 11, 231-252.

2. Weschler, C.J. Changes in indoor pollutants since the 1950s. Atmos. Environ. 2009, 43, 153-169. 
3. Shin, S.H.; Jo, W.K. Longitudinal variations in indoor VOC concentrations after moving into new apartments and indoor source characterization. Environ. Sci. Pollut. Res. 2013, 20, 3696-3707.

4. Nazaroff, W.W.; Weschler, C.J. Cleaning products and air fresheners: exposure to primary and secondary air pollutants. Atmos. Environ. 2004, 38, 2841-2865.

5. Long, C.M.; Suh, H.H.; Koutrakis, P. Characterization of indoor particle sources using continuous mass and size monitors. J. Air Waste Manag. Assoc. 2000, 50, 1236-1250.

6. Hammond, C.J. Chemical composition of household malodours-An overview. Flavour Frag. J. 2013, 28, 251-261.

7. Redlich, C.A.; Sparer, J.; Cullen, M.R. Sick-building syndrome. Lancet 1997, 349, 1013-1016.

8. Jones, A.P. Indoor air quality and health. Atmos. Environ. 1999, 33, 4535-4564.

9. Ahmad, I.; Tansel, B.; Mitrani, J.D. Effectiveness of HVAC duct cleaning procedures in improving indoor air quality. Environ. Monit. Assess. 2001, 72, 265-276.

10. Choi, J.H.; Han, S.Y.; Han, J.H.; Jo, H.J.; Kim, K.H. A preliminary study of hazardous pollutants released from the smoke of fish frying. Korean J. Odor Res. Eng. 2011, 10, 1-7.

11. Ko, Y.C.; Cheng, L.S.C.; Lee, C.H.; Huang, J.J.; Huang, M.S.; Kao, E.L.; Wang, H.Z.; Lin, H.J. Chinese food cooking and lung cancer in women nonsmokers. Am. J. Epidemiol. 2000, 152, $140-147$.

12. Kim, K.H.; Jahan, S.A.; Kabir, E. A review of diseases associated with household air pollution due to the use of biomass fuels. J. Hazard. Mater. 2011, 192, 425-431.

13. Kim, K.H.; Pandey, S.K.; Kabir, E.; Susaya, J.; Brown, R.J. The modern paradox of unregulated cooking activities and indoor air quality. J. Hazard. Mater. 2011, 195, 1-10.

14. Kim, K.H.; Kim, Y.H.; Kim, B.W.; Ahn, J.H.; Bae, M.S.; Brown, R.J. The reproducibility of indoor air pollution (IAP) measurement: A test case for the measurement of key air pollutants from the pan frying of fish samples. Sci. World J. 2014, 2014, doi:10.1155/2014/236501.

15. Kim, Y.H.; Kim, K.H. A statistical estimation approach for quantitative concentrations of compounds lacking authentic standards/surrogates based on linear correlations between directly measured detector responses and carbon number of different functional groups. Sci. World J. 2013, 2013, doi:10.1155/2013/241585.

16. Szulejko, J.E.; Kim, Y.H.; Kim, K.H. Method to predict gas chromatographic response factors for the trace-level analysis of volatile organic compounds based on the effective carbon number concept. J. Sep. Sci. 2013, 36, 3356-3365.

17. Kim, K.H.; Nguyen, H.T. Effects of injection volume change on gas chromatographic sensitivity determined with two contrasting calibration approaches for volatile organic compounds. J. Sep. Sci. 2007, 30, 367-374.

18. U.S. EPA Compendium Method TO-17. Determination of Volatile Organic Compounds in Ambient Air Using Active Sampling onto Sorbent Tubes. Available online: http://berkeleyanalytical.com/node/1703 (accessed on 13 November 2014).

19. Kim, K.H.; Lee, M.H.; Szulejko, J.E. Simulation of the breakthrough behavior of volatile organic compounds against Tenax TA sorbent tube sampler as a function of concentration level and sampling volume. Anal. Chim. Acta 2014, 835, 46-55. 
20. Szulejko, J.E.; Kim, K.H. Re-evaluation of effective carbon number (ECN) approach to predict response factors of "compounds lacking authentic standards or surrogates" (CLASS) by thermal desorption analysis with GC-MS. Anal. Chim. Acta 2014, 851, 14-22.

21. Kim, K.H.; Choi, G.H.; Choi, Y.J.; Song, H.N.; Yang, H.S.; Oh, J.M. The effects of sampling materials selection in the collection of reduced sulfur compounds in air. Talanta 2006, 68, 1713-1719.

22. Refsgaard, H.H.F.; Haahr, A.M.; Jensen, B. Isolation and quantification of volatiles in fish by dynamic headspace sampling and mass spectrometry. J. Agric. Food Chem. 1999, 47, 1114-1118.

23. Kim, Y.H.; Kim, K.H. An accurate and reliable analysis of trimethylamine using thermal desorption and gas chromatography-time of flight mass spectrometry. Anal. Chim. Acta 2013, 780, 46-54.

24. Arh, G.; Klasinc, L.; Veber, M.; Pompe, M. Modeling of the mass spectrometric response factors in non-target analysis. Acta Chim. Slov. 2010, 57, 581-585.

25. Nagata, Y. Measurement of Odor Threshold by Triangle Odor Bag Method, Odor Measurement Review; Ministry of Environment (MOE): Osaka, Japan, 2003; pp. 118-127.

26. Ahn, J.W.; Oh, K.Y.; Park, S.Y.; Lee, K.H.; Kim, Y.H.; Kim, K.H. Characterization of odorous emissions from decaying food samples: A case study on trimethylamine and ammonia. Korean $J$. Odor Res. Eng. 2007, 6, 172-182.

27. Jo, S.H.; Kim, K.H.; Park, S.J. Emission characteristics of reduced sulfur compounds due to cooking activities. Korean J. Odor Res. Eng. 2011, 10, 62-68.

28. Kim, B.W.; Ahn, J.H.; Kim, K.H.; Jo, S.H. Emission characteristics of odorous sulfur gases from food types: A case study on boiled egg, milk, canned meat, and strawberry. J. Korean Soc. Atmos. Environ. 2013, 29, 615-624.

29. Kabir, E.; Kim, K.H. An investigation on hazardous and odorous pollutant emission during cooking activities. J. Hazard. Mater. 2011, 188, 443-454.

30. Sundell, J. On the history of indoor air quality and health. Indoor Air 2004, 14, 51-58.

(C) 2014 by the authors; licensee MDPI, Basel, Switzerland. This article is an open access article distributed under the terms and conditions of the Creative Commons Attribution license (http://creativecommons.org/licenses/by/4.0/). 